\title{
The nature of V2 in Old French: Evidence from subject inversion in embedded clauses
}

\author{
LAURIE ZARING \\ Luther College \\ zarila01@luther.edu
}

\begin{abstract}
Old French (OF) is often characterized as a Germanic-style asymmetric V2 language, although this characterization is often questioned. The present study evaluates the nature of OF V2 from a quantitative perspective. An extensive set of data provided by syntactically annotated corpora shows that both IP and CP structure change over the OF period. Focusing on Germanic inversion - XVS word order - I argue that most of the attested inversion in OF occurs within an elaborated IP structure and that this type of subject inversion dwindles over time due to the decreasing use of null expletives. True Germanic-style embedded V2 does not appear until the late $12^{\text {th }}$ century, and is only rarely used throughout the $13^{\text {th }}$ century. Thus, OF is an asymmetric V2 language, but with a difference, namely in having an IP field that allows for apparent $\mathrm{V} 2$ orders and a CP field that is only marginally employed.
\end{abstract}

Key words: Old French, V2, embedded clauses, subject inversion, statistical analysis

\section{Résumé}

L'ancien français (AF) est généralement reconnu comme un langue V2, quoique cette assertion est souvent remise en cause. Cet article évalue le caractère V2 de l'AF d'un point de vue quantitatif. À partir d'un nombre significatif de données extraites d'un corpus annoté syntaxiquement, il appert que les structures tant du IP que du CP ont changé au cours des $12^{\mathrm{e}}$ et $13^{\mathrm{e}}$ siècles. Prenant comme point de départ l'inversion germanique - soit l'ordre XVS - je démontre que la plupart des inversions du sujet en AF apparaissent à l'intérieur d'un IP très articulé et que le déclin de l'inversion s'explique par la diminution des sujets nuls explétifs. Les enchâssées $\mathrm{V} 2$ de type germanique n'apparaissent qu'au $12^{\mathrm{e}}$ siècle et elles se propageront lentement tout au long du $13^{\mathrm{e}}$ siècle. Dès lors, on peut considérer l'AF comme une langue V2 asymétrique, mais de nature différente des langues germaniques, puisqu'il permet une réalisation apparente de l'ordre V2 à l'intérieur de IP, alors que sa réalisation au niveau du CP est marginale.

Mots clés: Ancien français, V2, proposition enchâssée, inversion du sujet, analyse statistique

I am grateful to the attendees of the October 2014 colloquium L'utilisation des corpus annotés pour comprendre le changement linguistique at the Université du Québec à Montréal, and to two anonymous reviewers for their insightful and helpful comments. Any errors or issues remaining are my own. 


\section{INTRODUCTION}

Old French (OF) is often characterized as a Germanic-style asymmetric V2 language. ${ }^{1}$ In other words, like Modern German, V2 is held to be obligatory in OF matrix clauses, but impossible in embedded clauses, with the exception of complements of bridge verbs (following Vance 1997, I refer to these as conjunctional clauses). First formalized in generative work by Adams (1987), Roberts (1993), and Vance (1997), this characterization has been more recently developed by Mathieu (2006, 2009, 2013), Sitaridou (2012), Salvesen (2013), Salvesen and Walkden (2013), and Salvesen and Bech (2014). Consider the example in (1), where both the matrix clause and the embedded conjunctional clause display inverted V2 (XVS) order.

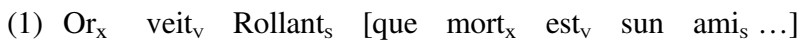

now sees Roland that dead is his friend

'Now Roland sees that his friend is dead ...'

(c. 1100, Rol 151.2041)

However, the V2 character of OF has been called into question on numerous occasions. One of the reasons for this is that V2 is readily attested in embedded nonconjunctional clauses, and researchers differ in particular with respect to the significance of inverted word orders found there. ${ }^{2}$ The present article aims to examine the nature of V2 in OF by evaluating from a quantitative perspective what Germanic inversion XVS word order - can tell us about the structure of embedded clauses in OF, whether it changes over time, and if it does, how. Germanic inversion is a particularly good lens through which to view V2 in OF because it has been found to vary in embedded clauses according to type of subject (full nominal or pronominal) and type of clause (conjunctional or nonconjunctional) and because its significance in indicating anything about clause structure is controversial. Drawing on a large set of data provided by syntactically annotated corpora, I show that both IP and CP structure change over the OF period. I argue that most of the attested Germanic inversion in OF occurs within the elaborated IP structure proposed by Labelle and Hirschbühler (to appear) and that the use of this structure dwindles over time due to the decreasing use of null expletives. True Germanic-style embedded V2, which involves movement to the CP field, does not appear until the late $12^{\text {th }}$ century and is only rarely used throughout the $13^{\text {th }}$ century. Thus, OF is an asymmetric V2 language, but with a difference, namely in having an IP field that allows for apparent V2 orders and a CP field that is only marginally employed.

\footnotetext{
${ }^{1}$ The following abbreviations are used: E12: early $12^{\text {th }}$ century; E13: early $13^{\text {th }}$ century; L12: late $12^{\text {th }}$ century; L13: late $13^{\text {th }}$ century; MCVF: Modéliser le changement: les Voies du français (corpus); OF: Old French; OV: object-verb; SF: Stylistic Fronting; SI: Stylistic Inversion; Sn: full nominal subjet; Sp: pronominal subject; SV: subject-verb; V1: verb first; V2: verb second; V3: verb third; VS: verb-subject.

${ }^{2}$ Other reasons have also been offered, notably the fact that matrix V1 and both matrix and embedded V3 are also readily attested in OF; see Ferraresi and Goldbach (2002), Rinke and Meisel (2009). I will not address that issue here.
} 


\section{EMBEDDED V2 IN OLD FRENCH}

We begin by taking a look at previous analyses of $\mathrm{V} 2$ in OF and, in particular, the ways in which they differ from one another. Researchers who maintain the Germanic V2 characterization described above generally attribute the abundantly attested XV order (possible since OF allows null subjects) to the presence in OF of Scandinavian-like Stylistic Inversion, either within the IP (Roberts 1993, Vance 1997, Salvesen 2011, Salvesen and Bech 2014), or in the left periphery of the clause (Mathieu 2006, 2009, 2013). Instances of Germanic inversion, or XVS order, are dealt with in two different ways. Because inversion with both full nominal (Sn) and pronominal (Sp) subjects occurs in conjunctional clauses, researchers suggest that this type of clause can accommodate matrix-style clause structure with an articulated CP that is the landing site for movement of the verb and the constituent that ends up in first position (as has been argued to be the case in Modern German). In nonconjunctional clauses, however, Sp-inversion is close to unattested and while Sn-inversion is attested, it is argued that XVSn order occurs insufficiently frequently to consider it anything more than an odd use of Stylistic Inversion where an overt subject remains within the VP. Thus, inversion in nonconjunctional clauses is considered sufficiently rare that it can be ignored.

Other researchers, however, interpret the presence of XVS order in nonconjunctional clauses as more significant. Lemieux and Dupuis (1995) and Côté (1995) both suggest that OF is a symmetric V2 language similar to Modern Icelandic. Others, however, make no claim for symmetric V2. Labelle (2007) and Labelle and Hirschbühler (2014, to appear) argue that XV(S) word orders in OF nonconjunctional clauses do not have the properties of Stylistic Inversion, while Labelle (2007) and Zaring (2011b) propose that XVS occurs frequently enough in all types of clauses that it needs to be taken into account in analyses of clause structure. All suggest that an articulated IP structure is available especially in the earliest part of the OF period and is responsible for XVS order in nonconjunctional clauses.

The disagreement as to how to treat V2 orders in OF embedded clauses stems from a variety of factors. In some cases, studies rely on a very small set of data, which makes it difficult to determine how significant the attested examples of inverted V2 orders are. In others, conclusions are based on only one or two texts which may not be representative of OF as a whole. Even when a large database is collected from a variety of texts, the question remains as to which portions of the OF period are represented. If the texts used come from a fairly narrow time span, it will be difficult to detect the possibility of some sort of change occurring across time. This is important, since Marchello-Nizia (1995), Côté (1995), Rouveret (2004), Zaring (2010, 2011b), and Labelle and Hirschbühler (this issue) all find notable differences between OF texts of the $12^{\text {th }}$ and $13^{\text {th }}$ centuries in the syntax of their clause structure. Finally, the genre of the text(s) used may also play a role. Most researchers maintain that the demands of meter and rhyme drive poets to use marginally available word orders to a much greater extent in their verse than would be found in prose. Results of studies could well vary if only a single genre were used, as is often the case. 
The syntactically annotated corpora available for OF provide a means of overcoming the issues involved in small or unrepresentative data sets and for evaluating statistically the significance of the attested XVS examples. The data examined here are drawn from the corpus Modéliser le changement/Voies du français (MCVF; Martineau et al 2010) and the corpus in the Penn Supplement to the MCVF (Kroch and Santorini 2012). They consist of 14,617 examples of V2 embedded clauses and have been drawn from nineteen verse and prose texts ranging over the approximately three centuries of OF. In the next section, I start with a detailed description of the database and, considering first inversion with pronominal subjects (Sp-inversion) and then inversion with full nominal subjects (Sn-inversion), proceed to a quantitative appraisal of Germanic inversion. For each subject type, I first provide an impressionistic discussion using percentage of occurrence to evaluate the rate of inversion and the role of clause type, change over time, and genre. This is followed by a discussion of the results of regression modeling testing the significance of each factor. We will see that while the results are less than conclusive, clause type and change over time do appear to play a role. However, it will be impossible to tease out the influence of genre versus change over time.

\section{THE DATA}

The data analyzed here consist of all of the embedded V2 clauses containing an overt subject contiguous to the inflected verb in nineteen syntactically parsed OF texts in the MCVF and the Penn Supplement. The texts range in date from the late $10^{\text {th }}$ to the late $13^{\text {th }}$ century and represent both verse and prose: ${ }^{3}$

(2) Early Old French (E12: texts prior to 1150): Leg, Alx, Rol, Brn (verse)

Late $12^{\text {th }}$ century (L12: 1150-1200): $M d F, Y v n, B o r V$ (verse); $Q L v$ (prose)

Early $13^{\text {th }}$ century (E13: 1200-1250): EusF, EusP (verse); Auc (Verse/Prose); Clr,

BorP, PsT, Qst, SAg, EusM (prose)

Late $13^{\text {th }}$ century (L13: 1250-1300): Cas, SR (prose)

Restricting the data to clauses with overt subjects allows us to discern more readily the rate at which inversion occurs - that is, to address the question "If a clause has an overt subject, how often does the subject follow the verb?". It also probes more directly for a German-like V2 structure because other means of generating XV order, such as Stylistic Fronting (SF), generally require the subject to be empty (null pronoun or trace). Ensuring that the inflected verb and the subject are contiguous eliminates from consideration those clear examples of Romance (a.k.a. free) inversion in which the subject is generally held to be either extraposed or within the $v \mathrm{P}$ - examples that cannot involve inversion resulting from V2 movement. ${ }^{4}$ In addition to word order

\footnotetext{
${ }^{3}$ See the list of Literary Works Used for the correspondence between the abbreviations used for the texts and their full titles, as well as the dates and the rationales for the dates assigned to them. The numbers provided are the locator numbers used in the MCVF corpus.

${ }^{4}$ Note, however, that contiguous VS strings are still structurally ambiguous, since they can result either from V2 movement or the subject remaining in $[\mathrm{Spec}, \nu \mathrm{P}]$, below the verb. See section 4 for discussion.
} 
(SV or VS) and subject-verb contiguity, the data were also coded for subject type (full nominal or pronominal) and clause type. Conjunctional clauses are those introduced by the complementizer que 'that'; these occur not only with bridge-type verbs but also as complements of nouns, adjectives, and other verbs and in conjunction with adverbial or prepositional elements (e.g., tant 'so (much)', ainz 'before', por 'in order', etc.). Adverbial clauses are introduced by se 'if', cum 'as/while', or quant 'when'. Non-Swh clauses are those from which a constituent (other than the subject, obviously) has been $w h$-extracted (and so include both relatives and interrogatives).

An anonymous reviewer suggests that it might be important to distinguish between relative clauses and other types of embedded clauses, given that apparent V2 in the former is often held to be Stylistic Fronting as in Scandinavian languages, as noted above. While my data analysis does not distinguish between interrogative and relative embedded clauses, the vast majority of the non-Swh (and the Swh) examples are relative clauses. Notably, my data indicate that unlike SF in Scandinavian, fronting of an XP is not obligatory but only a strong tendency $(60-95 \%$ are V2, not V1) in most texts in conjunctional, adverbial, and non-Swh clauses (at about the same rates in these three types). Moreover, in subject $w h$-clauses, where SF is most common in Scandinavian, the rates of V2 are much lower in my data than in the other types of clauses (about half and half V2 and V1), so fronting is in particular not obligatory here. These findings are consistent with Labelle (2007), Labelle and Hirschbühler (2014, to appear, this issue), who argue that Scandinavian-style SF does not exist in OF.

\subsection{Characteristics of Sp-inversion}

As Table 1 illustrates, inversion with pronominal subjects ( $\mathrm{Sp}$ ) is extremely rare. If all clause types are combined, only $1.3 \%$ of the just under 10,000 examples in the data have inverted order, and in any single text, no more than $2.5 \%$ are inverted.

Clause type does appear to play a role, as Figure 1 shows. Exceedingly few examples of inversion occur in nonconjunctional clauses - a single example is found across all texts in non-Swh clauses (Cas) and only six examples in adverbial clauses (one each in Yvn, PsT, Qst and $S R$; two in Cas). Inversion in conjunctional clauses is much more readily attested, although never abundantly and at rates that vary considerably across the texts. In this clause type, inversion is most frequent in Qst and Cas (6.1\% and 5.5\%, respectively), notably less so in $\mathrm{Yvn}, \mathrm{BorV}, \mathrm{Clr}$, $S A g$, and $S R(1.5 \%-3.8 \%)$, and even less frequent in BorP and $P S T(0.7 \%$ and $0.6 \%$, respectively). It is unattested prior to 1170 and also in $Q L v$, in $A u c$ (Verse), and in all three Eustache texts (EusF, EusP, EusM). This means that inversion occurs more often in prose than in verse; it is present in only two out of ten verse texts ( $Y v n$ and BorV) but shows up in nine out of ten prose texts. Finally, there does not appear to be any trend over time other than the fact that $\mathrm{Sp}$-inversion does not occur in the earliest texts. However, if the data are combined by approximate half centuries, there does appear to be a progressive increase as time goes by, as shown in Figure 2. 


\begin{tabular}{|c|c|c|c|c|c|c|c|}
\hline & \multicolumn{2}{|c|}{ Conjunctional } & \multicolumn{2}{|c|}{ Adverbial } & \multicolumn{2}{|c|}{ non-Swh } & \multirow[b]{2}{*}{ overall $\mathrm{N}$} \\
\hline & SV & VS & SV & VS & SV & VS & \\
\hline 980Leg & 2 & 0 & 7 & 0 & 8 & 0 & 17 \\
\hline 1090Alx & 10 & 0 & 10 & 0 & 34 & 0 & 54 \\
\hline 1100Rol & 70 & 0 & 67 & 0 & 64 & 0 & 201 \\
\hline 1120Brn & 7 & 0 & 9 & 0 & 49 & 0 & 65 \\
\hline $1160 \mathrm{MdF}$ & 162 & 0 & 203 & 0 & 209 & 0 & 574 \\
\hline 1170QLv & 260 & 0 & 171 & 0 & 186 & 0 & 617 \\
\hline 1170Yvn & 381 & 10 & 324 & 1 & 298 & 0 & 1014 \\
\hline 1190BorV & 150 & 4 & 132 & 0 & 165 & 0 & 451 \\
\hline $1205 \mathrm{Clr}$ & 511 & 20 & 299 & 0 & 229 & 0 & 1059 \\
\hline 1210BorP & 278 & 2 & 204 & 0 & 249 & 0 & 733 \\
\hline 1212EusF & 45 & 0 & 45 & 0 & 66 & 0 & 156 \\
\hline 1220PsT & 156 & 1 & 86 & 1 & 145 & 0 & 389 \\
\hline 1255AucVerse & 7 & 0 & 9 & 0 & 8 & 0 & 24 \\
\hline 1255AucProse & 105 & 3 & 80 & 0 & 43 & 0 & 231 \\
\hline 1225EusP & 67 & 0 & 75 & 0 & 65 & 0 & 207 \\
\hline 1225Qst & 510 & 33 & 432 & 1 & 371 & 0 & 1347 \\
\hline 1225EusM & 75 & 0 & 71 & 0 & 60 & 0 & 206 \\
\hline $1225 \mathrm{Sag}$ & 65 & 1 & 54 & 0 & 45 & 0 & 165 \\
\hline 1270Cas & 716 & 42 & 498 & 2 & 545 & 1 & 1804 \\
\hline 1279SR & 173 & 6 & 204 & 1 & 275 & 0 & 659 \\
\hline
\end{tabular}

Table 1: Number of examples of V2 Sp-inversion

The data above thus appear to confirm the conclusion reached by prior researchers with respect to $\mathrm{Sp}$-inversion: it occurs only in those clauses in which a matrix-like structure is held to be possible (conjunctional clauses). However, it is impossible to tell from percentages alone to what degree the generalizations noted above are significant. Fortunately, given a database of this size, statistical methods involving regression modeling can often shed some light on the situation. Ideally, we would want to see to what degree the value of our dependent variable (SV or VS word order) could be predicted by the independent variables clause type, date, and genre. Unfortunately,

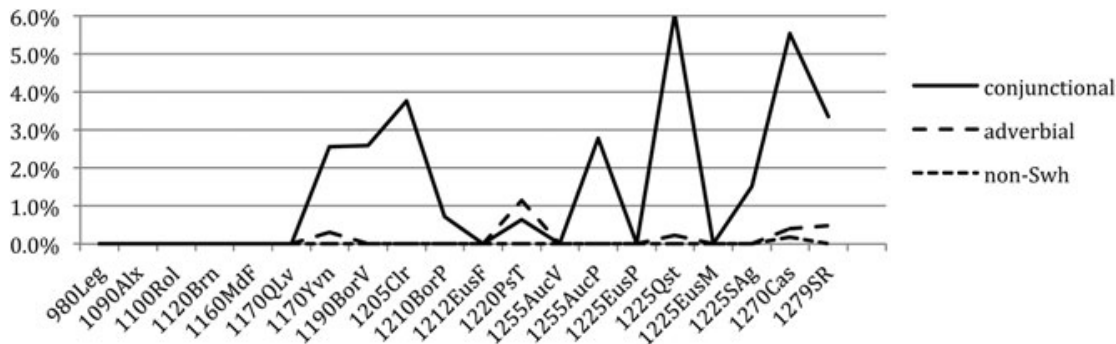

Figure 1: Rate of Sp-inversion by clause type 


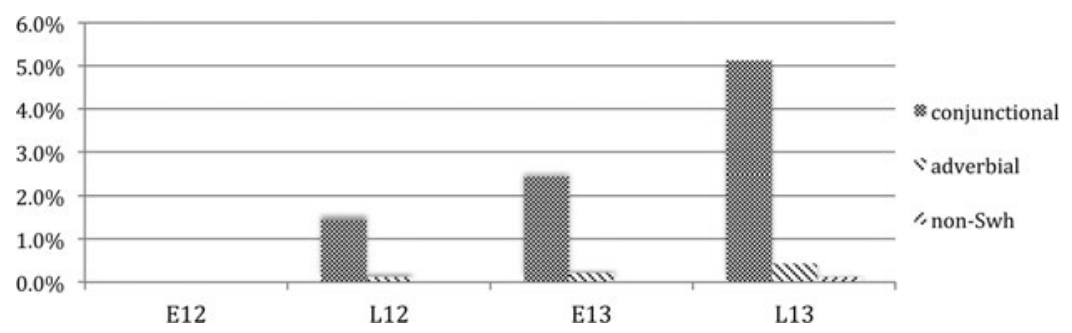

Figure 2: Binned rate of Sp-inversion by clause type

it is impossible to fit a model of this sort, but we can investigate the significance of clause type and genre together as predictors and of clause type and date together as predictors. ${ }^{5}$

Consider first the role of genre, since prose and verse appear to be so different. A binary logistic model was fit with word order as the dependent variable, and clause and genre as independent variables. The model itself is highly significant and shows significant main effects for clause type and genre, with no interaction effects. ${ }^{6}$ The correlation between word order and the predictors is weak but discernible. ${ }^{7}$ The model predicts very little inversion and difference between genres in nonconjunctional clauses, and more inversion and a notable difference between genres in conjunctional ones. Interestingly, however, the distinction between genres is opposite from what is expected. As noted above, most researchers maintain that the demands of meter and rhyme result in the use of marginally available word orders to a much greater extent in verse than in prose. If this were the case with Sp-inversion (clearly a marginal word order), we would expect more inversion in verse than in prose. This in fact not what we find: the model predicts more inversion in prose than in verse. Could change over time, then, be playing a role as well (or instead, since date and genre are so inextricably intertwined in this database)? A binary logistic regression with date and clause type as predictors fits a highly significant model with date but not clause type as a significant predictor and no interaction effects. ${ }^{8}$ If clause type is thus dropped as a variable, the resulting model is also highly significant. Here, the model is not a terribly good fit, but nevertheless predicts that Sp-inversion increases over time. ${ }^{9}$

\footnotetext{
${ }^{5}$ Most of the fourteen points in time (i.e., dates) in the data are represented by only one text and thus only one genre (1170 and 1225 are the only exceptions); thus for the examples taken from any single one these texts, the value of the date variable is always the same as is the value of the genre variable. This collinearity can be resolved only with difficulty. I leave this issue for future research.

${ }^{6} G=203.00 ; d f=5 ; p=<0.0001$; significance of clause type is $p=<0.0001$ and genre $p=<0.05$.

${ }^{7}$ The classification accuracy of the model is good $(C=0.811)$, but the amount of variance explained by the predictors is not high (Nagelkerke's $R^{2}=0.156$ ).

${ }^{8} p=<0.0001$; significance of date is $p=<0.0001$.

${ }^{9} G=30.02 ; d f=1 ; p=<0.0001$. Both classification accuracy and the variability accounted for are low $\left(C=0.633\right.$; Nagelkerke's $\left.R^{2}=0.023\right)$.
} 
The results of regression modeling are thus not completely clear. The fact that the model testing genre has greater classification accuracy than the one testing date could simply be a result of the fact that half of the verse texts in our database are earlier than 1170 , the date prior to which there is no Sp-inversion. Furthermore, the fact that clause type is not significant when tested with date could stem from the fact that there are so few examples in nonconjunctional clauses - perhaps what really shows an increase across time is inversion in conjunctional clauses. Finally, the fact that neither of the models accounts for much of the variation could be due to the rarity of inversion to begin with and to the fact that the database is fairly unbalanced - some texts are much smaller than others and thus have many fewer embedded clauses. We will tentatively conclude that both clause type and date are factors influencing the rate of Sp-inversion - inversion occurs only in conjunctional clauses and appears to increase over time after about 1170.

Finally, we will keep in mind the fact that the influence of genre vs. date on Spinversion cannot be gauged accurately from this database. As an anonymous reviewer quite rightly points out, the issue regarding the conflation of time and genre is a thorny one, given that there are only two known $12^{\text {th }}$ century OF prose texts, $Q L v$ and the Leis Willelme (a fairly short Anglo-Norman legal document with very few embedded clauses other than subject relatives). A separate analysis of the prose and verse texts is no more revealing. For both, regression modeling shows the overall model to be significant, but none of the main effects or interactions are. Plotting shows that only the conjunctional clauses are predicted to change over time in terms of (increasing) inversion. However, since the confidence intervals all include zero, the models are not to be trusted. This is likely due to the extremely small number of inversions that occur.

\subsection{Characteristics of Sn-inversion}

As noted in section 2, the significance of Germanic inversion with full nominal subjects $(\mathrm{Sn})$ remains contested in the literature, with some dismissing it as too infrequent to take into account (e.g., Mathieu 2013) and others taking the opposite stance (e.g., Labelle 2007). In our texts, SV order is strongly preferred with this type of subject, although not as strongly as with Sp: overall, 5.2\% of the 4,644 examples are inverted.

In contrast to Sp-inversion, only one text shows no Sn-inversion at all (see Table 2); ${ }^{10}$ the other texts have inverted subjects no less than $2 \%$ of the time. Rates vary widely across the texts, with Brn, Yvn, and $A u c V$ displaying the highest overall rates $\left(15.9 \%, 13.6 \%\right.$, and $38.5 \%$ respectively). ${ }^{11}$ Clearly, while Sn-inversion is still an infrequent word order, it is much less so than $\mathrm{Sp}$-inversion.

Figure 3 shows that clause type appears once again to be a factor. As with Spinversion, Sn-inversion is least frequent in wh-clauses $(1.6 \%$, averaged across all texts), notably more frequent in adverbial clauses (4.6\%), and most frequent in

\footnotetext{
${ }^{10}$ This is Leg, which has only four examples of embedded clauses total, none of them conjunctional. Note that $A u c$ (Prose) also shows no Sn-inversion, although $A u c$ (Verse) does.

${ }^{11} A u c$ (Verse) has only nine embedded clauses total, all of them adverbial, and the $38.5 \%$ figure should therefore be interpreted cautiously.
} 


\begin{tabular}{|c|c|c|c|c|c|c|c|}
\hline & \multicolumn{2}{|c|}{ Conjunctional } & \multicolumn{2}{|c|}{ Adverbial } & \multicolumn{2}{|c|}{ non-Swh } & \multirow[b]{2}{*}{ overall $\mathrm{N}$} \\
\hline & SV & VS & SV & VS & SV & VS & \\
\hline 980Leg & 0 & 0 & 1 & 0 & 3 & 0 & 4 \\
\hline 1090Alx & 10 & 0 & 3 & 1 & 9 & 1 & 24 \\
\hline 1100Rol & 25 & 6 & 41 & 7 & 39 & 0 & 118 \\
\hline 1120Brn & 14 & 3 & 11 & 3 & 33 & 5 & 69 \\
\hline $1160 \mathrm{MdF}$ & 68 & 8 & 74 & 1 & 102 & 0 & 253 \\
\hline 1170QLv & 172 & 26 & 164 & 25 & 94 & 2 & 483 \\
\hline 1170Yvn & 106 & 34 & 85 & 5 & 76 & 3 & 309 \\
\hline 1190BorV & 44 & 5 & 61 & 5 & 57 & 4 & 176 \\
\hline $1205 \mathrm{Clr}$ & 306 & 6 & 245 & 0 & 111 & 0 & 668 \\
\hline 1210BorP & 78 & 3 & 113 & 1 & 87 & 0 & 282 \\
\hline 1212EusF & 24 & 8 & 33 & 2 & 23 & 0 & 90 \\
\hline 1220PsT & 96 & 9 & 93 & 7 & 94 & 1 & 300 \\
\hline 1255AucVerse & 0 & 0 & 4 & 5 & 4 & 0 & 13 \\
\hline 1255AucProse & 24 & 0 & 27 & 0 & 22 & 0 & 73 \\
\hline 1225EusP & 19 & 7 & 22 & 2 & 23 & 0 & 73 \\
\hline 1225Qst & 204 & 12 & 183 & 0 & 157 & 0 & 556 \\
\hline 1225EusM & 29 & 0 & 22 & 2 & 20 & 0 & 73 \\
\hline $1225 \mathrm{SAg}$ & 14 & 1 & 8 & 0 & 8 & 0 & 31 \\
\hline $1270 \mathrm{Cas}$ & 325 & 13 & 286 & 6 & 144 & 1 & 775 \\
\hline 1279SR & 71 & 3 & 83 & 4 & 110 & 3 & 274 \\
\hline
\end{tabular}

Table 2: Number of examples of V2 Sn-inversion

conjunctional clauses $(8.1 \%)$. The texts vary as to whether inversion occurs more readily in conjunctional or nonconjunctional clauses: it occurs more frequently in conjunctional than nonconjunctional in $M d F, Y v n, E u s F, E u s P, Q s t$, and $S A g$; more frequently in nonconjunctional than conjunctional in Alx, Brn, AucV, EusM, and $S R$, and about equally in $R o l, Q L v, C l r, B o r P, P s T$, and Cas. The rates of inversion within each clause type vary considerably, but there appears to be a discernible decrease in the rate of inversion over time in both types of nonconjunctional clauses.

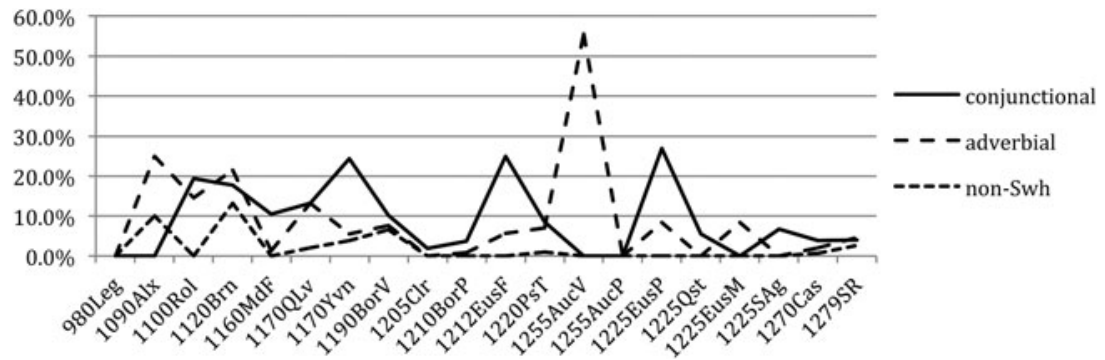

Figure 3: Rate of Sn-inversion by clause type 


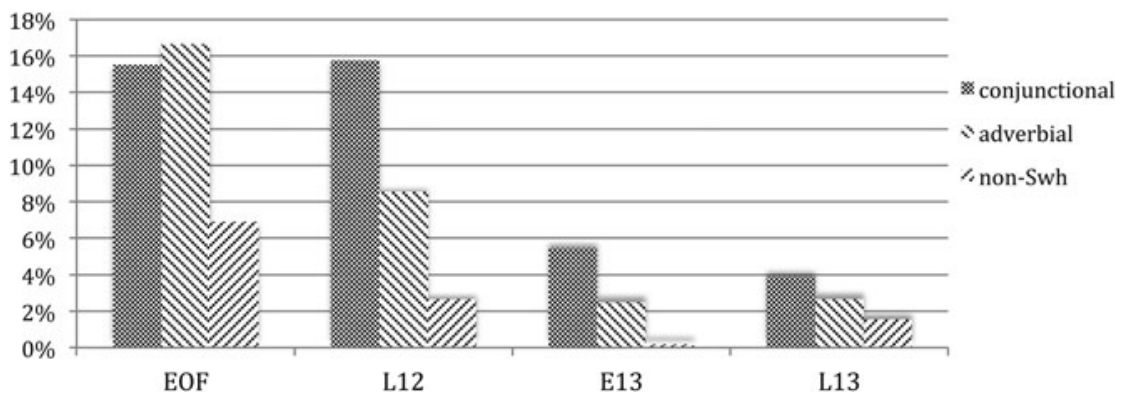

Figure 4: Rate of Sn-inversion by clause type

This trend is more apparent if the texts are combined by half-century, as in Figure 4. All clause types show a decrease. In nonconjunctional clauses, the trend levels off between E13 and L13. In conjunctional clauses, however, it begins between L12 and L13, showing a notable drop, and continues through L13.

Interestingly, the $12^{\text {th }}$ century prose QLv more closely resembles the verse texts of the $12^{\text {th }}$ century than it does the other prose texts, suggesting that change over time, rather than genre, is a factor. On the other hand, the $13^{\text {th }}$ century verse texts (EusF and EusP) more closely resemble the $\left(12^{\text {th }}\right.$ century) verse texts than the $13^{\text {th }}$ century prose texts. If texts of the different genres are contrasted, Sn-inversion appears to occur more readily in verse than in prose, in contrast to $\mathrm{Sp}$-inversion. With the exceptions of $L e g$ (which has so few examples) and $M d F$ (whose rate is more like prose), verse texts range between $8 \%$ and $38.5 \%$ inversion. With the exception of $Q L v$, prose texts range between $0.9 \%$ and $5.8 \%$ inversion.

To test the significance of these apparent trends, let us again consider what regression modeling might show us. A binary logistic model was fit with word order as the dependent variable and clause type and date as predictors. It shows that there is a highly significant but weak correlation between date and word order, but no effect for clause type and no interaction effects. ${ }^{12}$ The model is a slightly better fit than the corresponding Sp-inversion one, but not by much. Nonetheless, the model predicts a decrease in the rate of Sn-inversion for all three clause types; the most rapid decline does appear to be predicted for conjunctional clauses, but it is not dramatically different from adverbial clauses. If we substitute genre for date, as we did for $\mathrm{Sp}$-inversion, we see similar results. There is a highly significant but weak correlation between genre and word order, and we now also see a significant effect for clause type, although it just barely reaches the level of significance for adverbial clauses. ${ }^{13}$ The model predicts that inversion occurs more often in verse than in prose, with the difference being more marked in conjunctional than nonconjunctional clauses.

\footnotetext{
${ }^{12} G=138.7 ; d f=5 ; p=<0.0001 ;$ Nagelkerke's $R^{2}=0.088, \mathrm{C}=0.713$; significance of date is $p=<0.0001$.

${ }^{13} G=154.56 ; d f=5 ; p=<0.0001 ;$ Nagelkerke's $R^{2}=0.098, C=0.708$; the significance of genre is $p=<0.0001$ and of adverbial clauses is $p=0.0347$.
} 
So, once again, the regression results are less than completely clear. Inversion occurs more in verse than in prose and at different rates in different clause types, but it also is predicted to decrease over time if genre is not taken into account. We will again tentatively conclude that clause type and date are important factors in determining the presence of Sn-inversion, with date playing a larger role, and with the proviso that genre and date are too intertwined in the database to distinguish.

\section{ACCOUNTING FOR EMBEDDED V2}

The data examined in section 3 show that in embedded V2 clauses with a full nominal subject, Germanic inversion cannot be said to be anything more than infrequent. Nonetheless, it has a statistically significant presence that decreases over time in both conjunctional and nonconjunctional clauses, and the decrease occurs more or less in parallel in adverbial and conjunctional clauses. When the subject is pronominal, inversion occurs extremely rarely; it is unattested prior to 1170 and has a negligible presence in nonconjunctional clauses. In contrast, it increases in frequency in conjunctional clauses but is still never abundantly attested.

These facts lead to two sets of questions which we will address in this section. First, with respect to Sp-inversion, what are the properties of embedded clause structure in $\mathrm{OF}$ that enable XVSp in conjunctional clauses but not nonconjunctional ones? How might we explain its absence even in conjunctional clauses until the late $12^{\text {th }}$ century and its development but continued rarity thereafter? Second, considering Sn-inversion, what are the properties of embedded clause structure in OF that enable XVSn and that account for its more robust presence than Sp-inversion and in all clause types? How might we explain its decline over time? We begin with Sp-inversion.

\subsection{Embedded XVSp is true V2}

Vance (1997) and researchers since have noted that the top functional projection in IP is something of a subject magnet in OF, especially for Sp. SV order occurs with $94.8 \%$ of Sn in our data and with $98.7 \%$ of Sp. Furthermore, unlike Sn, Sp always immediately follows the complementizer when the order is SV, and when inverted, it always precedes negative and other short adverbs (e.g., mie 'not at all', bien 'well') held to occur above I/T. Labelle and Hirschbühler (2014, to appear) propose a clause structure which accounts for this fact, synthesizing Benincà and Poletto's (2004) left-peripheral structure with Rizzi's (1997) FinP and Rizzi and Shlonsky's (2006, 2007) and Rizzi's (2010) SubjP:

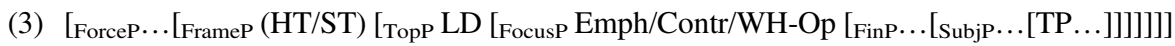
(HT = HangingTopic; ST = Scenic Topic; LD = Left Dislocated)

(Labelle and Hirschbühler, to appear, example (58))

SubjP, the top projection in the IP, is a criterial projection in Rizzi's sense; like the left-peripheral heads, it attracts a phrase for the purpose of interpretation at the interfaces. As Rizzi (2010: 25-26) notes, “...the argument selected as the subject 
is the starting point in the description of the event, which is presented as 'being about' the selected argument." SubjP formalizes this interpretation - the complement of Subj is the event that is about the argument attracted to [Spec,SubjP]. While there are ways for full nominal subjects to avoid being attracted to this position (see discussion below), OF subject pronouns must occupy this position due to the fact that they are weak pronouns - they are deficient in the sense of Cardinaletti and Starke (1999) and are licensed, according to Rizzi and Shlonsky (2007), by being in a Spec-head configuration with Subj. ${ }^{14}$

What, then, is the structure of embedded XVSp? Sp has to be in [Spec,SubjP], so $\mathrm{X}$ and $\mathrm{V}$ must be somewhere in the left periphery, just as they are in matrix V2. In other words, embedded V2 with Sp is a true Germanic-like V2 structure, as many researchers have argued. Early work (Roberts 1993, Vance 1997) argued for a recursive CP. As Labelle and Hirschbühler (2014, to appear) note, this can be captured in the structure in (4) following Holmberg's (2015) analysis of Germanic V2: V moves to Fin and $\mathrm{X}$ to $\left[\right.$ Spec,FinP]. ${ }^{15}$ A schematic derivation is shown in (4a), with an OF example in (4b). ${ }^{16}$ The attachment of a clitic to its host is indicated by + .
a. $\left[_{\text {ForceP }} q u e\left[_{\text {FinP }} X\right.\right.$ Fin $+\operatorname{Subj}+\mathrm{T}+v+\mathrm{V}\left[_{\text {SubjP }} \operatorname{Sp} \operatorname{Subj}+\mathrm{T}+v+\mathrm{V}\left[\left[_{\mathrm{TP}} \mathrm{T}+v+\mathrm{V}\right.\right.\right.$ $\left.\left.\left.\left[{ }_{v \mathrm{P}} \mathrm{Sp} v+\mathrm{V}[\mathrm{vP} \vee]\right]\right]\right]\right]$

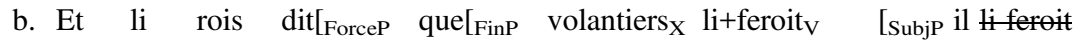 and the king says that willingly to.her+would.make he [TP li feroit [ ${ }_{\nu \mathrm{P}}$ il [ $\left[\mathrm{vP} \mathrm{li}+\right.$ feroit volantiers $\mathrm{X}_{\mathrm{X}} \ldots$ amor et joie et conpaignie $\left.\left.\left.\left.]\right]\right]\right]\right]$ love and joy and company
'And the king says that he would gladly provide her with love, joy, and companionship.'
(c. 1170, Yvn, 71.2506)

The fact that Sp-inversion occurs only in conjunctional clauses suggests that the V2 movement shown above cannot occur in nonconjunctional clauses. Why might this be so? Let us assume with Holmberg (2015), among others, that Fin has a generalized EPP feature which attracts both elements. I propose that this feature is not inherent to Fin, but rather that Fin inherits this feature from Force. Chomsky (2008: 143) proposes the mechanism of feature inheritance to explain why $\mathrm{T}$, which appears to be the locus of $\phi$-features and Tense, is not a phase boundary. He argues that $\mathrm{T}$ manifests these features only if selected by $\mathrm{C}$ (i.e., by a head in the left periphery) and this is explained if $\mathrm{T}$ inherits the features from C. Likewise, the constituent-attracting nature of Fin for $\mathrm{V} 2$ in $\mathrm{OF}$ is dependent on the type of clause it occurs in, which is determined by the left-peripheral head(s) above it.

\footnotetext{
${ }^{14}$ Deficient pronouns contrast with strong pronouns in a wide variety of ways, including being able to refer to both humans and nonhumans, having a expletive form, and forming prosodic units with other lexical items, all of which are true for OF Sp.

${ }^{15}$ Or higher in the left periphery, if focused; see Frey $(2004,2006)$ and Labelle and Hirschbühler (to appear).

${ }^{16} \mathrm{An}$ analysis of this sort has also been proposed by Poletto (2002) for Rhaetoromance, by Wolfe (2015) for Old Spanish, and by Ledgeway (2008 and elsewhere) for early Romance in general.
} 
I suggest that in OF, the generalized EPP feature is a property of the Force head que, the complementizer that occurs only in conjunctional clauses. In other words, the EPP feature is not found on the left-peripheral head in nonconjunctional clauses, making Sp-inversion (and left-peripheral embedded V2) impossible there.

Finally, we noted above that there is a diachronic dimension to the structure in (4a): it does not appear to have existed prior to 1170 and increases in frequency after that date, especially in prose texts, although it is always rare. I take this to indicate that the generalized EPP feature did not occur on any embedded left peripheral head prior to 1170 . Why might it have developed after this point in time? I suggest that this is possibly connected to a variety of other changes occurring in the language in the course of the $12^{\text {th }}$ and $13^{\text {th }}$ centuries, many of them having to do with clause structure. Marchello-Nizia (1995), noting a decline in the use of V2 OV order in matrix clauses between the early $12^{\text {th }}$ and early $13^{\text {th }}$ century, argues that one of the primary instigators of this was a change from word-based to phrase-based stress assignment which enabled postverbal stress-based focus of constituents. Clearly, this change would have repercussions for the information-structural use of the left periphery. Both Marchello-Nizia and Labelle and Hirschbühler (this issue) find such repercussions; Labelle and Hirschbühler note that the grammar of the $12^{\text {th }}$ century is statistically closer to the German use of the left periphery, while that of the $13^{\text {th }}$ century is closer to Scandinavian. In addition, the nature of V1 and V3 clauses changes over this period, as documented by Rouveret (2004), Labelle (2007), and Labelle and Hirschbühler (to appear), which these authors attribute to changes in left-peripheral clause structure. Movement possibilities to the middle periphery (above $\nu \mathrm{P}$ ) also undergo changes, as Zaring (2010, 2011a) attests. Finally, conjunctional clauses undergo change as well during this period: as Zaring and Hirschbühler (1997) note, they can appear early on preceded by $c e$ 'this, it' in any grammatical function, but this becomes restricted to complements of prepositions in the $13^{\text {th }}$ century.

In general, the changes noted above can be characterized by an evolution from a freer, discourse-function influenced word order to a much more fixed word order reminiscent of Modern French. As learners struggled to make sense of the variety of word orders exhibited in their environment, they may have (however briefly, in the grand scheme of things) posited the EPP feature on que as a way of understanding the nature of V2 in their language. It is also conceivable that the Force head does not intrinsically have the EPP feature but is assigned it by virtue of being an argument of some head $(\mathrm{V}, v, \mathrm{~A}$, or $\mathrm{P})$. In this case, learners might have, for a time, reinterpreted the lexical properties of heads taking conjunctional complements as be able to assign the EPP feature. This lexical property would help explain why the types of clauses which permit embedded left-peripheral V2 vary fairly widely across languages (see Holmberg 2015: 358) and how the type of microparametric variation attested in Salvesen and Walkden (2013) might have arisen. It should be noted, however, that matrix-like embedded V2 never truly caught on in OF, remaining in the $13^{\text {th }}$ century an extremely marginal grammar. 


\subsection{Sn-inversion is IP-V2}

In contrast to embedded Sp-inversion, Sn-inversion is not marginal - although it is fairly infrequent - and it is attested in all clause types from the earliest texts in our data. In addition, $\mathrm{Sn}$-inversion decreases in frequency over time, unlike Sp-inversion, which increases. Given these differences, it is clear that Sn-inversion cannot result from the matrix-like V2 structure we saw in (4). Labelle and Hirschbühler (to appear) argue that throughout the OF period, an IP-structure is available in all types of clauses that includes a functional projection FP situated between SubjP and TP. Drawing on evidence from V3 clauses, they propose that this is the unmarked position targeted by fronted constituents in embedded OF clauses. Examples from nonconjunctional clauses are shown in (5): a V3 example in (5a) and an apparent V2 example with a null subject in (5b); the fronted constituent (the $X$ in SXV or $\mathrm{XV})$ is in italics. Note that Labelle and Hirschbühler's structure, following Benincà and Poletto (2004), places wh-operators in FocP, just above FinP. There is thus no way for the subject to be in TopP and the fronted phrase in FinP.

a. pour Dieu nous dites[FocP Ou[SubjP vous[FP cest suaire[TP preïstes]]]]. for God us tell where you this shroud took

'For God, tell us from where you took this shroud.' $\quad$ (c. 1190, BorV, 55.847)

(Labelle and Hirschbühler, to appear, (67))

b. ... Conter...[FocP En queu terre[SubjP[FP $\operatorname{aler[TP}$ le couvint]]]] tell in which land to.go him was.needed '...tell...in which land he had to go'

(Labelle and Hirschbühler, to appear, example (63))

This is also plausibly the structure for Sn-inversion. In these cases, I suggest that the $\mathrm{Sn}$ remains within the $v \mathrm{P}$, following Labelle (2007) and Mathieu (2013). However, in the analysis proposed above, SubjP is the highest IP projection and should attract the Sn to its Spec. If the Sn stays within the $v \mathrm{P}$, what satisfies the Subject Criterion? Rizzi (2006, 2010) and Rizzi and Shlonsky (2006, 2007) argue that a variety of strategies allow subjects to avoid being attracted to [Spec,SubjP]. One of these involves the use of a null expletive ( pro $_{\text {expl }}$ ) in [Spec,SubjP]. Its presence is what allows apparent that-t violations in canonical null-subject languages

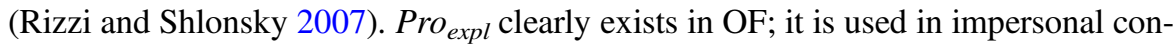
structions, as in (6).

(6) [Forcep [FinP Asez est [Subjp pro $_{\text {expl }}$ [TP $_{\text {TP }}$ est ${ }_{\nu \mathrm{P}}$ asez melz qu' il i perdent lé rather is

better that they there lose the

chefs ]]]]]

heads

'It is rather better that they lose their heads there.'

(c. 1100, Rol, 3.38)

OF also allows apparent that-t violations, as in (7).

(7) Et se ce est cil [CP que $O p$ je croi[CP que $O p$ soit mes peres ... ] and if this is he that I believe that is my father

'And if this is he who I believe is my father ...' $\quad$ (c. 1225, Qst, 28.682)

Thus, embedded Sn-inversion would have the structure in (8). 
(8) cel odur $\left[_{\mathrm{FocP}}\right.$ Que $\left[_{\mathrm{FinP}}\left[_{\mathrm{SubjP}}\right.\right.$ pro $_{\text {expl }}\left[_{\mathrm{FP}}\right.$ en paraïs $\left[_{\mathrm{TP}}\right.$ gettent $\left[_{\nu \mathrm{P}}\right.$ li flur gettent the fragrance which in paradise throw the flowers [vp gettent que ]]]]]] 'the fragrance which the flowers give off in paradise ...'

This analysis makes an interesting prediction: the order $X P$ auxiliary $S$ $V_{\text {pastparticiple }}$ should not be possible in nonconjunctional clauses. ${ }^{17}$ Assuming the periphrastic structure argued for in Zaring (2011a), which postulates Aux and PastPart heads below TP and above $\nu \mathrm{P}$, a subject must follow the past participle if it is not fronted to SubjP. There is no other spot between the auxiliary and the participle for it to occupy. ${ }^{18}$

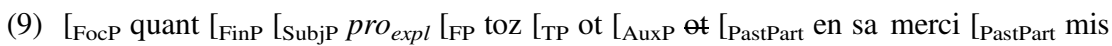
when all had in his mercy put

[vP Eustaces [vP mis ses anemis en sa merci ...]]]]]]]]]

Eustace his enemies

'When Eustace had all his enemies at his mercy ...'

(c. 1212, EusF, 42.554)

This order would be possible in the conjunctional clause V2 structure (within CP) argued for in section 4.1, but only once it became available in the latter part of the $12^{\text {th }}$ century. So, an additional prediction made here is that this order should not be found in conjunctional clauses prior to that. Testing these predictions is challenging; periphrastic verbs are not particularly abundant, especially with inversion. Moreover, 53 of the 70 examples with inversion found in my data have the past participle fronted, so that it is impossible to tell the precise position of the subject. The remaining 17 examples have the subject between the auxiliary and the participle. Notably, only two occur in nonconjunctional clauses (one in EusP, one in Cass) and only three of the 15 in conjunctional clauses occur prior to 1170 (one in Rol, one in $B r n$, one in $Q L v$ ). So, while not unattested, this order is exceedingly rare. I take this to confirm that the inverted subject in nonconjunctional clauses, and in early conjunctional clauses, remains in the $\nu \mathrm{P}$.

If the inverted $\mathrm{Sn}$ remains in the $v \mathrm{P}$ in these clauses, what then is the difference between this type of inversion and Romance inversion, which, as noted in section 3.0, is often also held to involve an in situ subject? Possibly not much. A full investigation of this question is beyond the scope of this article, since it would need to consider matrix as well as embedded clauses. However, a preliminary survey of clear instances of Romance inversion (where a constituent intervenes between the finite verb and the $\mathrm{Sn}$ ) in my data indicates that the majority can be accounted for under the current analysis. Salvesen and Bech (2014), working exclusively with matrix clauses, also argue that inverted Sn remains in $v \mathrm{P}$, although this runs counter to most analyses, which argue for Germanic-style inversion in matrix clauses. In contrast, Belletti (2004) offers an analysis in which $\mathrm{Sn}$ moves to a $v \mathrm{P}$-left periphery. I leave open for further research which analysis might best capture Romance inversion in OF.

\footnotetext{
${ }^{17} \mathrm{I}$ am grateful to the reviewers for calling this to my attention.

${ }^{18}$ Zaring (2011a) argues that non-objects preceding the past participle are adjoined to PastPartP.
} 
It is, then, the structure in (8) that enables Sn-inversion throughout the OF period and that accounts for the differences between $\mathrm{Sp}$ - and $\mathrm{Sn}$-inversion. As Labelle and Hirschbühler (to appear) note, it is not a marginal structure, but is used in readily attested occurrences of V3 in both matrix and embedded clauses, and, as I have argued, its availability allows apparent V2, including Sn-inversion, to occur in all types of embedded clauses as well. We saw in section 3.2, however, that the rate of Sn-inversion decreases over time. This decrease is arguably tied to the fact noted by Zimmerman $(2009,2014)$ that the use of pro $_{\text {expl }}$ in impersonal constructions also declined over the OF period, giving way to the overt pronominal expletive $i l$, especially in embedded clauses. ${ }^{19}$ As the use of pro $_{\text {expl }}$ declines, the occurrence of embedded Sn-inversion would have to as well.

If the presence of expletive pro is sufficient to satisfy the Subject Criterion and allow the thematic subject to remain in the $v \mathrm{P}$, why is this not possible with overt expletives? A possibility lies in the degree to which pro $_{\text {expl }}$ and $i l$ differ in the defectiveness of their $\phi$-features. Il conceivably has both person and number features like its English counterpart it ([3 PERS, Sg NUM]; see Radford 2009: 302) since verbs agreeing with it are always third-person singular. Pro $_{\text {expl }}$, on the other hand, must have only a person feature [3 PERS], since postverbal subjects occurring in sentences with it can be either singular or plural. The presence of the number feature on the overt expletive would preclude it from functioning to allow $\mathrm{Sn}$ inversion. Alternatively, the overt/covert distinction may be an issue for the PF component only, since on many conceptions of Minimalist syntax phonetic features are irrelevant to the syntax. See Alboiu (2009).

\section{Conclusion}

A statistical analysis of the large set of data examined here has allowed us to sketch out a more nuanced understanding of the nature of embedded V2 in Old French. Drawn from a wide variety of texts extending across the entire OF period, the data show that $\mathrm{Sp}$-inversion, the most reliable indicator in OF of matrix-like embedded $\mathrm{V} 2$, is attested only in conjunctional clauses. Drawing on prior analyses, I have proposed that V2 here targets FinP in the left periphery of embedded clauses headed by the Force head que, from which Fin inherits the generalized EPP feature that attract the verb and fronted phrase. This much confirms many prior claims that OF has German-like asymmetric V2. However, we have seen that this is not true of the entire period: Sp-inversion is unattested prior to the late $12^{\text {th }}$ century and its rate increases through the $13^{\text {th }}$ century As a result, we can say at most that part of the period has asymmetric V2. Even this claim must be tenuous at best - the grammar enabling it is never more than marginally used. The role of genre in Sp-inversion is difficult to determine, since most of the verse comes from the $12^{\text {th }}$ century and

\footnotetext{
${ }^{19}$ This analysis might predict that expletive $i l$ might be found associated with a thematic subject that has remained in the $v \mathrm{P}$ and a fronted constituent in FP, producing a V3 structure. I leave the testing of this prediction for future research.
} 
most of the prose from the $13^{\text {th }}$. But the fact that it is found more in prose than in verse (when in fact we would expect the opposite) suggests that the crucial factor is change over time.

As for Sn-inversion, the data show that it is attested throughout the OF period, that it occurs in all clauses types, and that it has a notably higher rate of occurrence and a different pattern of change over time than $\mathrm{Sp}$-inversion. These facts argue for a structure distinct from that proposed for Sp-inversion. I have argued that the articulated IP structure proposed by Labelle and Hirschbühler (to appear) enables not only SXV and XV (as they propose) but also the XVSn of Sn-inversion. The fact that Sninversion occurs at non-negligible rates supports their contention, contra Mathieu (2013), that these word orders do not result from Stylistic Inversion. The data indicate that the rate of Sn-inversion decreases over time, which I have argued to be the result of the declining use of pro $_{\text {expl }}$, the null expletive which satisfies the Subject Criterion and allows the subject to stay in $v \mathrm{P}$. The role of genre in influencing the results is difficult to discern here, just as it was with Sp-inversion. On the one hand, the $12^{\text {th }}$ century prose $Q L v$ has a rate of Sn-inversion similar to the other texts of the $12^{\text {th }}$ century, even though they are verse. This could indicate that genre does not influence the rate of use. On the other hand, the verse texts of the $13^{\text {th }}$ century have a rate of Sninversion that resembles the $12^{\text {th }}$ century verse texts more than the $13^{\text {th }}$ century prose texts. It is possible that both change over time and genre play a role here. If the articulated IP structure had a more prominent place in $12^{\text {th }}$ century OF grammar than in the $13^{\text {th }}$ century, then perhaps the $Q L v$ is simply unusual prose in using it at the same rate as verse. Moreover, $13^{\text {th }}$ century poets were undoubtedly influenced by the models of $12^{\text {th }}$ century verse available to them and perhaps they employed a grammar typical of that verse but which was no longer nearly as prominent in the prose of their time.

Clearly, certain questions and issues are left unaddressed. One of these is the function of FP - is it a Criterial position? Does it have topic/focus properties similar to elements in the left periphery? Another question has to do with the position of null subjects suggested by the analysis here. Researchers from Adams (1987) to Zimmerman (2014) have argued that null subjects in OF must be licensed by a c-commanding verb. In the analysis proposed here, however, they would necessarily occupy [Spec,SubjP], above the verb in T. How might their distribution be captured in this case? ${ }^{20}$ Finally, it would be useful as well to explore other statistical models (for example, mixed-methods) that might allow a better analysis of the unbalanced, highly collinear, and dependent data available to us. However, we conclude for now that $\mathrm{V} 2$ in $\mathrm{OF}$ is different in nature from the Germanic languages. Matrix-like embedded V2 is essentially unavailable, and the apparent V2 orders that are attested are due to movement within an articulated IP.

\footnotetext{
${ }^{20}$ The resolution of the null subject issue is beyond the scope of this article. But see Walkden (2013) for an approach to null subjects in Old English which might prove illuminating for Old French.
} 


\section{Literary WORKS Cited}

Alx (c. 1090; date assigned by the Penn Supplement). La vie de Saint Alexis. Ed. Christopher Storey, 1968. Genève: Droz.

Auc (c. 1225; middle of period designated by editor). Aucassin et Nicolette: Chantefable du XIIIe siècle. Ed. Mario Roques, 1936. Paris: Champion.

BorP (c. 1210; date assigned by the Penn Supplement). Le roman du Graal: manuscrit de Modè-Pseudo-Robert de Boron. Ed. Bernard Cerquiglini, 1981. Paris: Union Générale d'Édition.

BorV (c. 1190; date assigned by the Penn Supplement). Le roman de l'estoire dou Graal. Ed. William A. Nitze. 1927. Paris: Champion.

Brn (c.1120; date assigned by the Penn Supplement). The Anglo-Norman voyage of St Brendan. Ed. Ian Short and Brian S Merrilees, 1979. Manchester: Manchester University Press.

Cas (c. 1270; editor's best estimate of the precise date). Le roman de Cassidorus. Ed. Joseph Palermo, 1964. Paris: Editions Picard.

Clr (c. 1205; date assigned by the Penn Supplement). La conquête de Constantinople. Ed. Philippe Lauer, 1924. Paris: Champion.

EusF (c. 1212; date assigned by the Penn Supplement) Pierre de Beauvais. La vie de Saint Eustache. Ed. John Roberts Fisher, 1917. The Romanic Review, 8(1): 1-67.

EusM (c. 1225; middle of period designated by editor). La vie de Saint Eustace. Version en prose française du XIIIe siècle. Ed. Jessie Murray, 1929. Paris: Honoré Champion.

EusP (c. 1225; average of estimates by Paul Meyer and Holger Petersen). La vie de Saint Eustache. Poème français du XIIIe siècle. Ed. Holger Petersen, 1928. Paris: Champion.

Leg (c. 980; date assigned by the Penn Supplement). Saint Léger. Étude de la langue du manuscrit de Clermont-Ferrand, suivie d'une édition critique du texte avec commentaire et glossaire. Ed. Joseph Linskill, 1937. Paris: Droz.

$M d F$ (c. 1160; date generally used in the generative literature). Les lais de Marie de France. Ed. Jean Rychner, 1973. Paris: Champion.

PsT (c. 1220; date used in Labelle and Hirschbühler 2014). Der sogenannte poitevinische Pseudo-Turpin. Nach den Handschriften mitgetheilt. [The so-called Poitevin pseudoTurpin. Told according to the manuscripts.] Ed. Theodor Auracher, 1877. Zeitschrift für romanische Philologie 1:259-336.

$Q L v$ (c. 1170; date generally used in the generative literature). Li quatre livre des reis. Ed. Ernst Robert Curtius, 1911. Gesellschaft für romanische Literatur, no. 9. Dresden, Halle: Max Niemeyer.

Qst (c. 1225; date assigned by the Penn Supplement). La Queste del Saint Graal. Ed. Christiane Marchello-Nizia, édition électronique basée sur A. Pauphilet. 1923. Paris: Champion.

Rol (c. 1100; date assigned by the Penn Supplement). La chanson de Roland. Ed. Gérard Moignet, Gérard, 1972. Paris: Bordas.

SAg (c. 1225; middle of period designated by editor). Sermon anonyme sur sainte Agnès, texte du XIIIe siècle. Ed. Robert Taylor, 1969. Travaux de linguistique et de littérature de l'Université de Strasbourg 7: 241-253.

SR (c. 1279; date assigned by the Penn Supplement). Somme des vices et des vertus. Ed. Ann Brooks Tysor, 1949. M.A. thesis, University of North Carolina. 1-85.

Yvn (c. 1170; date assigned by the Penn Supplement). Les romans de Chrétien de Troyes, édités d'après la copie de Guiot (Bibl. nat. fr. 794). Ed. Mario Roques, 1960. Paris: Champion. 


\section{REFERENCES}

Adams, Marianne. 1987. From Old French to the theory of pro-drop. Natural Language and Linguistic Theory 5(1): 1-32.

Alboiu, Gabriela. 2009. Null expletives and case. In Romance linguistics 2007: selected papers from the 37th Linguistic Symposium on Romance Languages (LSRL), ed. Pascual José Masullo, Erin O'Rourke, and Chia-Hui Huang, 1-18. Amsterdam: John Benjamins.

Belletti, Adriana. 2004. Aspects of the low IP area. In The Structure of CP and IP, ed. Luigi Rizzi, 16-51. Oxford: Oxford University Press.

Benincà, Paola, and Cecilia Poletto. 2004. Topic, focus and V2: Defining the CP sublayers. In The Structure of CP and IP, ed. Luigi Rizzi, 52-75. Oxford: Oxford University Press.

Cardinaletti, Anna, and Michal Starke. 1999. The syntax of structural deficiency: A case study of the three classes of pronouns. In Clitics in the languages of Europe, ed. Henk van Riemsdijk, 145-233. Berlin: Mouton de Gruyter.

Chomsky, Noam. 2008. On phases. In Foundational issues in linguistic theory: Essays in honor of Jean-Roger Vergnaud, ed. Robert Freidin, Carlos P. Otero, and Maria Luisa Zubizarreta, 133-166. Cambridge, MA: MIT Press.

Côté, Marie-Hélène. 1995. Concurrence structurale, conditions d'appréhensibilité et changement syntaxique: la chute de la structure V2 en français. Canadian Journal of Linguistics 40(2): 165-200.

Ferraresi, Gisella, and Maria Goldbach. 2002. V2 syntax and topicalisation in Old French. Linguistiche Berichte 189: 3-25.

Frey, Werner. 2004. The grammar-pragmatics interface and the German prefield. Sprache und Pragmatik 52: 1-39.

Frey, Werner. 2006. Contrast and movement to the German prefield. In The architecture of focus, ed. Valéria Molnár and Susanne Winkler, 235-264. Berlin: Mouton de Gruyter.

Holmberg, Anders. 2015. Verb Second. In Syntax - Theory and analysis. An international handbook, volume I, ed. Tibor Kiss and Artemis Alexiadou, 342-383. Berlin: Mouton De Gruyter.

Kroch, Anthony, and Beatrice Santorini. 2012. Penn supplement to the MCVF corpus of historical French. University of Pennsylvania. <http://www.ling.upenn.edu/hist-corpora $>$.

Labelle, Marie. 2007. Clausal architecture in early Old French. Lingua 117(1): 289-316.

Labelle, Marie, and Paul Hirschbühler. 2014. Déplacement stylistique à gauche de verbes non conjugués en ancien et en moyen français. Corpus 13: 191-219.

Labelle, Marie, and Paul Hirschbühler. To appear. Leftward Stylistic Displacement (LSD) in medieval French. In From micro-change to macro-change, ed. Éric Mathieu and Robert Truswell. Oxford: Oxford University Press.

Labelle, Marie, and Paul Hirschbühler. This issue. Topic and Focus in Old French V1 and V2. Canadian Journal of Linguistics 63(2).

Ledgeway, Adam. 2008. Satisfying V2 in Early Romance: Merge vs. Move. Journal of Linguistics, 44(2): 437-470.

Lemieux, Monique, and Fernande Dupuis. 1995. The locus of verb movement in non-asymmetric verb second languages: The case of Middle French. In Clause structure and language change, ed. Adrian Battye and Ian Roberts, 80-109. Oxford: Oxford University Press.

Marchello-Nizia, Christiane. 1995. L'évolution du français: Ordre des mots, démonstratifs, accent tonique. Paris: Armand Colin.

Martineau, France, Paul Hirschbühler, Anthony Kroch, and Yves Charles Morin. 2010. Corpus MCVF annoté syntaxiquement. Modéliser le changement: les Voies du français, 
Département de français, Université d'Ottawa. CD-ROM <http://continent.uottawa.ca/fr/ corpus/corpusmcvf/structure/>.

Mathieu, Éric. 2006. Stylistic fronting in Old French. Probus 18(2): 219-266.

Mathieu, Éric. 2009. On the Germanic properties of Old French. In Historical syntax and linguistic theory, ed. Paola Crisma and Giuseppe Longobardi, 344-357. Oxford: Oxford University Press.

Mathieu, Éric. 2013. The left periphery in Old French. In Research in Old French: The state of the art, ed. Deborah Arteaga, 327-350. Dordrecht: Springer.

Poletto, Cecilia. 2002. The left-periphery of V2-Rhaetoromance dialects: A new view on V2 and V3. In Syntactic microvariation, ed. Sjef Barbiers, Leonie Cornips and Susanne van der Kleij, 214-242. Electronic publications of Meertens Instituut. <http://www.meertens.knaw.nl/books/synmic/pdf/poletto.pdf>

Radford, Andrew. 2009. Analysing English sentences. Cambridge: Cambridge University Press.

Rinke, Esther, and Jürgen M. Meisel. 2009. Subject-inversion in Old French: Syntax and information structure. In Proceedings of the Workshop "Null-Subjects, Expletives, and Locatives in Romance" (Arbeitspapier 123), ed. Georg A. Kaiser and E. M. Remberger, 93-130. Konstanz: Fachbereich Sprachwissenschaft, Universität Konstanz.

Rizzi, Luigi. 1997. The fine structure of the left periphery. In Elements of grammar: Handbook of generative syntax, ed. Liliane Haegeman, 281-337. Dordrecht: Kluwer.

Rizzi, Luigi. 2006. On the form of chains: Criterial positions and ECP effects. In Wh-movement: Moving on, ed. Lisa L. S. Cheng and Norbert Corver, 98-133. Cambridge, MA: MIT Press.

Rizzi, Luigi. 2010. On some properties of criterial freezing. In The Complementizer phase: Subjects and operators, ed. E. Phoevos Panagiotidis, 17-32. Oxford: Oxford University Press.

Rizzi, Luigi, and Ur Shlonsky. 2006. Satisfying the Subject Criterion by a non subject: English locative inversion and Heavy NP Shift. In Phases of interpretation, ed. Mara Frascarelli, 341-361. Berlin: Mouton de Gruyter.

Rizzi, Luigi, and Ur Shlonsky. 2007. Strategies of subject extraction. In Interfaces + recursion =language?: Chomsky's Minimalism and the view from syntax-semantics, ed. Uli Sauerland and Hans-Martin Gartner, 115-160. Berlin: Mouton de Gruyter.

Roberts, Ian. 1993. Verbs and diachronic syntax. Dordrecht: Kluwer.

Rouveret, Alain. 2004. Les clitiques pronominaux et la périphérie gauche en ancien français. Bulletin de la Société de linguistique de Paris 99(1): 181-237.

Salvesen, Christine Meklenborg. 2011. Stylistic Fronting and remnant movement in Old French. In Romance languages and linguistic theory: Selected papers from 'Going Romance' Nice 2009, ed. Janine Bern, Haike Jacobs, and Tobias Scheer, 323-342. Amsterdam: John Benjamins.

Salvesen, Christine Meklenborg. 2013. Topics and the left periphery: a comparison of Old French and Modern Germanic. In In search of Universal Grammar. From Old Norse to Zoque, ed. Terje Lohndal, 131-171. Amsterdam: John Benjamins.

Salvesen, Christine Meklenborg, and Kristin Bech. 2014. Postverbal subjects in Old English and Old French. In Oslo Studies in Language 6: Corpus-based studies in contrastive linguistics, ed. Signe Oksefjell Ebeling, Atle Grønn, Kjetil Rå Hauge, and Diana Santos, 201-228.

Salvesen, Christine Meklenborg, and George Walkden. 2013. Diagnosing embedded V2 in Old French and Old English. Paper presented at the $15^{\text {th }}$ Diachronic Generative Syntax conference. Ottawa: University of Ottawa, August 3, 2013. 
Sitaridou, Ioanna. 2012. A comparative study of word order in Old Romance. Folia Linguistica 46(2): 553-604.

Vance, B. 1997. Syntactic change in Medieval French. Verb-second and null subjects. Dordrecht: Kluwer.

Walkden, George. 2013. Null subjects in Old English. Language Variation and Change 25(2): $155-178$.

Wolfe, Sam. 2015. The nature of Old Spanish verb second reconsidered. Lingua 164: 132-155.

Zaring, Laurie. 2010. Changing from OV to VO: More evidence from Old French. Ianua. Revista Philologica Romanica 10: 1-18.

Zaring, Laurie. 2011a. On the nature of OV and VO order in Old French. Lingua 121(12): $1831-1852$.

Zaring, Laurie. 2011b. On the nature of embedded V2 in Old French. Paper presented at the $13^{\text {th }}$ Diachronic Generative Syntax conference. Philadelphia: University of Pennsylvania, June 5, 2011.

Zaring, Laurie, and Paul Hirschbühler. 1997. Qu'est-ce que ce que: The diachronic evolution of a French complementizer. In Parameters of morphosyntactic change, ed. Ans van Kemenade and Nigel Vincent, 353-379. Cambridge: Cambridge University Press.

Zimmerman, Michael. 2009. On the evolution of expletive subject pronouns in Old French. In Proceedings of the workshop Null-subjects, Expletives, and Locatives in Romance (Arbeitspapier 123), ed. Georg A. Kaiser and Eva-Maria Remberger, 63-92. Konstanz: Fachbereich Sprachwissenschaft, Universität Konstanz.

Zimmerman, Michael. 2014. Expletive and referential subject pronouns in Medieval French. Berlin: Mouton de Gruyter. 